\title{
Bacteriological profile in conjunctival, lacrimal sac, and nasal specimens and conjunctival normalization time following external, endoscopic, and transcanalicular multidiode laser dacryocystorhinostomy
}

\author{
Perfil bacteriológico e tempo de normalização conjuntival de espécimes de conjuntiva, saco lacrimal e \\ nasais após dacriocistorrinostomia externa, endoscópica e transcanalicular com laser de multi diodo
}

Melike Balikoglu-Yilmaz ${ }^{1,2}$, Ayse Banu Esen ${ }^{3}$, Tolga Yilmaz 2 , Umit Taskin ${ }^{4}$, Muhittin Taskapili², M. Faruk Oktay ${ }^{4}$, Emine Sen ${ }^{5}$, Timur Kose ${ }^{6}$

\begin{abstract}
Purpose: To compare the conjunctival, lacrimal sac, and nasal flora cultures and conjunctival normalization time following external (EX-), endoscopic (EN-), and transcanalicular multidiode laser (TC-) dacryocystorhinostomy (DCR) and to evaluate the relationship between culture positivity and surgical success. We further performed antibiotic sensitivity analyses for lacrimal sac culture samples. Methods: A total of 90 patients with primary acquired nasolacrimal duct obstruction were recruited and divided into EX-DCR $(n=32), E N-D C R(n=28)$, and TC-DCR $(n=30)$ groups. Conjunctival, nasal, and lacrimal sac cultures and antibiograms were analyzed.

Results: In all three groups, coagulase-negative Staphylococcus (CNS) was predominantly isolated preoperatively from the conjunctiva, nose, and lacrimal sac and postoperatively from the conjunctiva. Preoperative and postoperative conjunctival culture positivity rates were similar between all the groups $(p>0.05)$. A statistically significant difference in the growth rate of culture in the lacrimal sac was observed between the three groups $(p=0.001)$. CNS and Staphylococcus aureus cultures were predominantly sensitive to linezolid, teicoplanin, tigecycline, vancomycin, and mupirocin. Conjunctival normalization times were similar between the three groups ( $p>0.05$ ). Anatomical and functional success rates were not found to be significantly correlated with preoperative conjunctival and lacrimal sac culture positivity ( $p>0.05)$

Conclusions: Similar rates of preoperative and 1-week postoperative conjunctival culture positivity were observed in all the groups; a significantly lower bacterial growth rate was observed in postoperative conjunctival cultures. CNS was the most commonly isolated organism. Bacterial growth rates in the lacrimal sac samples were significantly higher in the EN-DCR group. Bacterial growth rates obtained preoperatively from the conjunctival and lacrimal sac culture samples were not correlated with DCR success.
\end{abstract}

Keywords: Conjunctiva; Dacryocystorhinostomy; Nasolacrimal duct; Antibiotic sensitivity tests; Staphylococcus aureus, Transcanalicular multidiode laser

\section{RESUMO}

Objetivo: Comparar a flora conjuntival, do saco lacrimal e nasal com o tempo de normalização após dacriocistorrinostomia (DCR) externa (EX-), endoscópica (EN-) e transcanalicular a laser de multi diodo (TC-) para correlacionar a positividade da cultura com o sucesso cirúrgico, assim como identificar a sensibilidade aos antibióticos em amostras de saco lacrimal.

Métodos: Neste estudo prospectivo, 90 pacientes com obstrução do canal nasolacrimal adquirida primária foram incluídos e divididos em grupos EX-DCR $(n=32)$, EN-DCR ( $n=28)$ e TC-DCR $(n=30)$. Culturas e antibiogramas conjuntivais, nasais e do saco lacrimal foram analisados.

Resultados: Staphylococcus coagulase-negativo (CNS) foi o organismo predominante isolado no pré-operatório (conjuntiva e nariz), no transoperatório (saco lacrimal) e pós-operatório (conjuntiva), nos 3 grupos. Taxas de positividade de cultura da conjuntiva pré- e pós-operatórias nos três grupos foram semelhantes $(p>0,05)$. A diferença nas taxas de crescimento do saco lacrimal dos três grupos foi estatisticamente significativa $(p=0,001)$. CNS e . aureus foram mais sensiveis a linezolida, teicoplanina, a tigeciclina, vancomicina e mupirocina. O tempo de normalização conjuntival foi semelhante nos três grupos $(p>0,05)$. Não houve relação estatisticamente significativa entre as taxas de sucesso anatômicas e funcionais e a positividade da cultura conjuntival e de saco lacrimal pré-operatória $(p>0,05)$.

Conclusões: Pacientes submetidos a EX-DCR, EN-DCR, e TC-DCR apresentaram positividades de cultura conjuntival semelhantes no pré-operatório e na 1a semana pós-operatória. Houve uma redução significativa na taxa de crescimento das culturas da conjuntiva pós-operatórias. O organismo mais comumente isolado foi o CNS. A taxa de crescimento de bactérias a partir do saco lacrimal foi significativamente maior no grupo PT-DCR. O crescimento bacteriano da conjuntiva no pré-operatório e de amostras do saco lacrimal no transoperatório não se relacionaram com o sucesso da DCR.

Descritores: Conjuntiva; Dacriocistorinostomia; Ducto nasolacrimal; Testes de sensibilidade microbiana; Lasers semicondutores

\section{INTRODUCTION}

Nasolacrimal duct obstruction (NLDO) is a common ophthalmic presentation and has been reported to represent $3 \%$ of clinic visits ${ }^{(1)}$. NLDO is typically treated using either external (EX-) or endoscopic (EN-) dacryocystorhinostomy (DCR) or using transcanalicular multi- diode laser (TC-) to create a fistula between the lacrimal sac and nasal cavity, allowing tear flow. Each type of DCR is associated with specific advantages and disadvantages ${ }^{(2,3)}$. The traditional DCR procedure (EX-DCR) can cause cutaneous scarring, disruption of the medial canthus, and excessive intra-operative bleeding. Advantages of EN-DCR
Submitted for publication: August 10, 2015

Accepted for publication: February 10, 2016

Department of Ophthalmology, Faculty of Medicine, Izmir Katip Celebi University, Izmir, Turkey. 2 Department of Ophthalmology, Bagcilar Education and Research Hospital, Istanbul, Turkey.

3 Department of Microbiology and Clinical Microbiology Bagcilar Education and Research Hospital, Istanbul, Turkey.

Department of Otorhinolaryngology, Bagcilar Education and Research Hospital, Istanbul, Turkey.

Department of Ophthalmology, Ulucanlar Eye Education and Research Hospital, Ankara, Turkey.

${ }^{6}$ Department of Biostatistics and Medical Informatics, Faculty of Medicine, Ege University, Izmir, Turkey.
Funding: The present study was supported by the Institutional Review Board of Bagcilar Education and Research Hospital, Istanbul, Turkey (\#1852).

Disclosure of potential conflicts of interest: None of the authors have any potential conflicts of interest to disclose.

Corresponding author: Melike Balikoglu-Yilmaz. Department of Ophthalmology, Izmir Katip Celebi University. Faculty of Medicine. Izmir - Turkey - E-mail: drmelkebalkoglu@yahoo.com

Approved by the following research ethics committee: Bagcilar Education and Research Hospital (\#2011/13). 
and TC-DCR include the absence of a cutaneous scar and decreased operative duration. The new TC-DCR has demonstrated safe utility in elderly patients with systemic diseases ${ }^{(4-8)}$.

A unique combination of stasis and moisture in NLDO may create an optimal environment for the growth of lacrimal sac flora. Numerous bacterial species have been implicated in chronic dacryocystitis ${ }^{(9)}$. Furthermore, the types of isolated pathogens may change over time ${ }^{(10,11)}$. Accurate identification of the pathogens responsible for chronic dacryocystitis is critical for the selection of appropriate antibiotic agents ${ }^{(12)}$. Therefore, to the best of our knowledge, we were the first to compare the three types of DCR with respect to culture results with a view to select an appropriate antibiotic cover following each technique. Here we aimed to compare bacterial species preoperatively isolated from the involved and contralateral conjunctival samples and from the involved and contralateral nasal and lacrimal sac samples together with those isolated from the involved side conjunctival samples after performing EX-DCR, EN-DCR and TC-DCR in patients. The present study also aimed to assess the relationship between culture results and success rates of each DCR type, identify the bacterial species most commonly responsible for dacryocystitis, and evaluate corresponding antibiograms of cultured isolates.

\section{METHODS}

This prospective, non-randomized, and comparative clinical study was conducted at the Departments of Ophthalmology and Otorhinolaryngology of Bagcilar Education and Research Hospital in Istanbul, Turkey, between February 2011 and December 2012. The present study was conducted in accordance with the ethical guidelines of the Declaration of Helsinki after obtaining approval from the Institutional Ethics Committee. All patients provided informed consent.

We included patients with symptoms of epiphora who were diagnosed with PANDO upon detection of obstruction on syringing and probing or on performing antero-posterior and lateral dacryocystography using lipiodol. Exclusion criteria were as follows: previous nasal or nasolacrimal system surgery; pre-saccal obstruction; canalolithiasis; lacrimal system tumor; previous trauma to the ocular and nasal regions; bony deformity; abnormal intranasal anatomy, including an advanced deviated nasal septum, middle turbinate (MT) hypertrophy, or concha bullosa; nasal polyps; and previous treatment with topical or systemic antibiotics a month prior to undergoing DCR.

A total of 90 patients scheduled to undergo primary DCR were included in the present study. Data regarding clinical outcomes of this study population were previously reported ${ }^{(13)}$. Patients were non-randomly assigned into the EX-DCR $(n=32), E N-D C R \quad(n=28)$, and TC-DCR ( $n=30)$ groups according to the type of DCR requested. Patients were provided information regarding the EX-DCR, EN-DCR, and TC-DCR methods. Surgeries were performed in a standardized manner according to previously published methods ${ }^{(13)}$. EX-DCR and TC-DCR were performed by three ophthalmic surgeons (M.B.Y., T.Y., and M.A.) who were highly experienced in EX-DCR and moderately experienced in TC-DCR. EN-DCR was performed by an experienced otolaryngologist (U.T.).

The techniques used in the present study were as follows:

EX-DCR: A 15-20-mm straight incision was created medial to the angular vein at the level of the anterior lacrimal crest. The lacrimal fossa was exposed by blunt dissection of the orbicularis muscle and opening of the periosteum prior to D-shaped osteotomy to create a bone window extending from the medial canthal tendon to the proximal nasolacrimal duct, with the posterior lacrimal crest at the posterior aspect. An $\mathrm{H}$-shaped incision was then created in the lacrimal sac and nasal mucosa using a surgical blade, and opposing mucosal flaps were sutured with absorbable $6 / 0$ vicryl. To prevent canalicular "cheese wiring," a bicanalicular silicone tube was placed and tied gently and the skin was sutured with continuous 6/0 polypropylene to provide good cosmesis.
EN-DCR: The maxillary fissure on the lateral nasal wall was initially identified before the creation of a $2 \times 1.5-\mathrm{cm}$ mucoperiosteal flap. The lacrimal bone was then exposed and drilled into with a diamond burr to expose at least a $1 \times 1-\mathrm{cm}$ area of the sac while protecting the uncinate process. A lateral nasal wall opening was created through the MT axilla. The sac medial wall bulged from the new opening upon the application of pressure over the sac. A vertical incision was then created in the sac and the medial wall was excised, followed by the insertion of a bicanalicular silicone tube from both the upper and lower puncta and tying of the free ends in the nasal cavity.

TC-DCR: We first dilated the superior and inferior puncta, followed by the insertion of a semirigid $600-\mu \mathrm{m}$ quartz multidiode laser fiber (Multidiode S30 OFT, INTERmedic Arfran, Madrid, Spain) through the canaliculus. The fiber was then rotated in an oblique orientation such that it rested against the medial lacrimal sac wall. Laser parameters used were as follows: power, $10 \mathrm{~W}$ and pulse length, 400 milliseconds, adjusted as necessary with an interval between pulses of 400 milliseconds. We used a $0^{\circ}, 4-\mathrm{mm}$ rigid nasal endoscope as the nasal probe and a periosteal elevator to deviate the MT medially to provide good exposure for the last procedure. We were also able to provide protection from the laser probe using this technique. The red aiming beam of the laser probe was then directed at the lateral nasal wall and used to create an ostium of adequate size. The laser was then used to ablate the lacrimal bone and nasal mucosa. This osteotomy site was immediately anterior and inferior to the root of the MT. Osteotomy was widened using the laser prior to the placement of bicanalicular silicone tubes once the laser probe was withdrawn.

Postoperatively, all patients were prescribed oral antibiotics, an anti-inflammatory drug, combination antibiotic-steroid eye drops four times a day for 1 week, and a nasal corticosteroid spray twice a day after nasal irrigation with $0.9 \%$ normal saline for 1 month to eradicate fibrin clots.

For each patient, conjunctival and nasal (inferior meatus) samples were obtained preoperatively from both the involved and contralateral sides. Lacrimal sac cultures were obtained directly from the lacrimal sac during DCR. Antibiograms for cultures from the lacrimal sac were also evaluated. Patients were re-examined weekly during the first 2 postoperative months, and subsequently followed up on a monthly basis. We continued to postoperatively obtain and analyze conjunctival cultures from the involved side each week until negative culture results were obtained twice. Silicone tubes were removed at the 2-month postoperative visit. Anatomical success was defined as endoscopic endonasal ostium patency and successful nasolacrimal irrigation without reflux. Functional success was defined as resolution of epiphora. Conjunctival normalization time was defined as the time from DCR until the second negative result of conjunctival culture from the involved side.

\section{ConJunctival, LACRIMAL, AND NASAL CULTURE}

Preoperative conjunctival and nasal and postoperative conjunctival, culture samples were inoculated onto 5\% sheep's blood, chocolate, MacConkey, and Sabouraud dextrose agar media (Premed, Turkey). Lacrimal sac culture samples were also inoculated on the same media as well as on anaerobic agar and thioglycolate broth media during DCR. Both blood and chocolate agars were incubated at $37^{\circ} \mathrm{C}$ in a $5 \%-10 \% \mathrm{CO}_{2}$ atmosphere for $24-72$ hours. MacConkey agar was incubated at $37^{\circ} \mathrm{C}$ in ambient air for $24-72$ hours. Sabouraud Dextrose agar was incubated at both $25^{\circ} \mathrm{C}$ and $37^{\circ} \mathrm{C}$ for 21 days. Anaerobic agar and thioglycolate broth media were incubated at $37^{\circ} \mathrm{C}$ under anaerobic conditions using the GasPak Anaerobe Pouch System (BD, USA) for 48 hours. Organisms isolated from samples were examined using Gram's stain and $\mathrm{KOH}$ mount and identified using the Vitec 2 compact system (bioMerieux, Marcy-l'Etoile, France). Susceptibility testing of isolated species was performed using the same system. 


\section{Statistical analysis}

IBM SPSS Statistics, version 20.0 software (SPSS Inc. Chicago, IL, USA) was used for all statistical analyses. Continuous variables were presented as mean \pm standard deviation and categorical data were presented as numbers and percentages. The chi-square $\left(\chi^{2}\right)$ test or Fisher's exact test was used to compare categorical variables between the groups. Numerical variables were compared between the three groups using analysis of variance (one-way ANOVA) or the Kruskal-Wallis test. The Mann-Whitney U test or Fisher's exact test was used for pairwise comparisons of variables found to significantly differ between groups according to the Kruskal-Wallis test. The McNemar test was used to analyze culture positivity before and after DCR. All hypothesis controls were applied at a significance level of $\alpha=0.05$ ( $p$ values of $\leq 0.05$ were considered to be statistically significant).

\section{RESULTS}

The present study included 69 (77\%) female and 21 (23\%) male patients, with a mean age of $49.8 \pm 18.9$ (range, 4-86) years. EX-DCR, EN-DCR, and TC-DCR were used in 32, 28, and 30 patients, respectively. The mean follow-up time was $16.1 \pm 2.5$ (range, 10-20) months. Descriptive patient characteristics are presented in table 1.

Bacteria isolated from conjunctival, nasal, and lacrimal sac samples are presented in table 2. Coagulase-negative Staphylococcus (CNS) was the predominant organism isolated from pre- and postoperatively obtained first-week conjunctival samples (14.4\% for involved eyes and $12.2 \%$ for other eyes preoperatively, and $11.1 \%$ for involved eyes postoperatively) as well as from the preoperative nasal mucosa (67.8\% for both sides) and lacrimal sac samples (22.2\%). Bacteroides fragilis was the only anaerobic bacterial strain isolated from lacrimal sac samples; that sample was from a single patient in the EX-DCR group.

EX-, EN- and TC-DCR groups had similar conjunctival culture positivity rates of $46.9 \%, 42.9 \%$, and $30 \%$, respectively, at the first preoperative week and $18.8 \%, 3.6 \%$, and $13.3 \%$, respectively, at the first postoperative week (preoperative, $p=0.372$; and postoperative, $p=0.196$; Table 3). Conjunctival culture positivity rates were significantly lower after EX- and EN-DCR ( $p=0.022$ and $p=0.001$, respectively). Although there was a trend toward a lower conjunctival culture positivity rate after TC-DCR, this trend was not statistically significant $(p=0.267)$. The conjunctival growth rate was $40.0 \%$ (36 patients) at the involved site and $23.3 \%$ (21 patients) at the contralateral site, with a statistically significant difference observed $(p=0.004)$. In contrast, the nasal growth rate was $98.9 \%$ (89 patients) at the involved site and $97.8 \%$ (88 patients) at the contralateral side, with no statistically significant difference observed ( $p=1.000)$.

The lacrimal sac culture growth rate was significantly higher in the EN-DCR (85.7\%) group than in the EX-DCR (40.6\%) and TC-DCR groups $(46.7 \%, p=0.001)$. Comparison between conjunctival flora and lacrimal sac flora isolated from the involved side demonstrated a significantly higher lacrimal sac growth rate (56.7\%, 51 patients) than the conjunctival growth rate $(40.0 \%, 36$ patients; $\mathrm{p}=0.011)$. Conjunctival normalization times were similar between the three groups $(1.5 \pm 1.1$, $1.0 \pm 0.2$, and $1.2 \pm 0.5$ weeks for EX-, EN-, and TC-DCR, respectively; $\mathrm{p}=0.166$; Table 3).

Anatomical and functional success rates were not found to be associated with preoperative conjunctival and lacrimal sac culture positivity rates within the three groups and among all patients included in the present study ( $p>0.05$ for all; Table 4).

CNS and Staphylococcus aureus were most sensitive to linezolid, teicoplanin, tigecycline, vancomycin, and mupirocin (antibiotic sensitivity, 100\% for all) (Table 5) and most resistant to penicillin G and tetracycline (antibiotic resistance, $95.5 \%$ and $62.5 \%$, respectively).

\section{DISCUSSION}

The microbiological properties of the lacrimal sac in PANDO patients has been a topic of interest in recent years as the spectrum of organisms constituting the lacrimal flora appears to have changed due to many factors ${ }^{(11,14,15)}$. Despite a large number of comparative studies on DCR, none have previously compared three separate methods in terms of microbiological findings. Accordingly, we believe that the present study is the first to compare clinico-bacteriological outcomes between conjunctival, nasal, and lacrimal sac samples isolated following three types of DCR (EX, EN, and TC).

The pathogens responsible for chronic dacryocystitis are typically gram-positive bacteria, including CNS, S. aureus, and Streptococci(16). Staphylococci, particularly S. aureus, have now replaced Streptococci as the most common cause of chronic dacryocystitis following the discovery of effective antibiotics, such as penicillin and cephalosporins, to which they have demonstrated greater resistance ${ }^{(10,11)}$. Coden et al. ${ }^{(17)}$ evaluated culture samples from purulent lacrimal sac contents in 236 patients with dacryocystitis who were undergoing DCR and reported that the most common bacteria were S. epidermidis (27.3\%) and S. aureus (22.1\%), with a positive culture rate of 52\%. Owji et al. ${ }^{(15)}$ studied lacrimal sac cultures from the involved side and conjunctival cultures from the involved and normal sides of patients with NLDO and chronic dacryocystitis, and they found that the most frequently isolated organisms from the lacrimal sac and conjunctiva of the involved side were S. aureus (47.5\% and $47.5 \%$, respectively) and S. epidermidis (22.5\% and 20\%, respectively). On the other hand, the most frequently isolated organisms from the conjunctiva of the normal side and from that of the control healthy subjects were S. epidermidis (60\% and $60 \%$, respectively) and S. aureus (47.5\% and 30\%, respectively) ${ }^{(15)}$. Pradeep et al. ${ }^{(18)}$ reported that the most common isolates from lacrimal sac specimens in chronic dacryocystitis cases were CNS and S. aureus (71\% and $14 \%$, respectively). In the present study, the most commonly isolated organisms from the involved conjunctival side during the preoperative and first postoperative week, involved nasal side preoperatively, lacrimal sac preoperatively, and contralateral conjunctival and nasal sites preoperatively were S. epidermidis (14.4\%, $11.1 \%, 67.8 \%, 22.2 \%, 12.2 \%$, and $67.8 \%$, respectively) and S. aureus

Table 1. Patient characteristics

\begin{tabular}{lccccc}
\hline & EX-DCR $(\mathbf{n = 3 2})$ & EN-DCR $(\mathbf{n = 2 8})$ & TC-DCR $(\mathbf{n = 3 0})$ & Total $(\mathbf{n}=\mathbf{9 0})$ & $\boldsymbol{p}$ value \\
\hline Age (years) & $52.2 \pm 16.5$ & $46.8 \pm 20.9$ & $50.1 \pm 19.8$ & $49.8 \pm 18.9$ & $0.544^{\mathrm{a}}$ \\
Female: male & $26: 6$ & $20: 8$ & $23: 7$ & $69: 21$ & $0.669^{\mathrm{b}}$ \\
Laterality (right: left) & $17: 15$ & $14: 14$ & $15: 15$ & $46: 44$ & $0.961^{\mathrm{b}}$ \\
Follow-up time (months) & $17.0 \pm 2.1$ & $13.9 \pm 2.3^{\mathrm{d}, e}$ & $17.3 \pm 1.3$ & $16.1 \pm 2.5$ & $<0.001^{\mathrm{c}}$ \\
\hline
\end{tabular}

EX-DCR= external dacryocystorhinostomy; EN-DCR= endoscopic dacryocystorhinostomy; TC-DCR= transcanalicular dacryocystorhinostomy with multidiode laser.

${ }^{*}=$ Values are presented as mean \pm standard deviation; ${ }^{a}=$ One-way ANOVA; ${ }^{b}=$ Chi-square $\left(\chi^{2}\right)$ test; ${ }^{c}=$ Kruskal-Wallis test; ${ }^{d}=p<0.001$ compared with the EX-DCR group, Mann-Whitney U test; ${ }^{\mathrm{e}}=p<0.001$ compared with the TC-DCR group, Mann-Whitney $\mathrm{U}$ test. 
Table 2. Results of preoperative conjunctival, nasal, and lacrimal sac cultures as well as of postoperative conjunctival cultures

\begin{tabular}{|c|c|c|c|c|c|c|c|c|}
\hline & \multicolumn{2}{|c|}{ EX-DCR $(n=32)$} & \multicolumn{2}{|c|}{ EN-DCR $(n=28)$} & \multicolumn{2}{|c|}{ TC-DCR $(n=30)$} & \multicolumn{2}{|c|}{ Total $(n=90)$} \\
\hline & I & $\mathbf{C}$ & I & $\mathbf{C}$ & I & $\mathbf{C}$ & I & $\mathbf{C}$ \\
\hline \multicolumn{9}{|l|}{ Preoperative conjunctival culture } \\
\hline No bacteria isolated & $17(53.1)$ & $21(65.6)$ & $16(57.1)$ & $20(71.4)$ & $21(70.0)$ & $28(93.3)$ & $54(60.0)$ & $69(76.7)$ \\
\hline MSSA & $1(3.1)$ & $2(6.3)$ & $1(3.6)$ & $3(10.7)$ & $3(10.0)$ & $1(3.3)$ & $5(5.6)$ & $6(6.7)$ \\
\hline MRSA & - & - & $1(3.6)$ & $1(3.6)$ & $1(3.3)$ & $1(3.3)$ & $2(2.2)$ & $2(2.2)$ \\
\hline Staph. epidermidis & $6(18.8)$ & $7(21.9)$ & $6(21.4)$ & $4(14.3)$ & $1(3.3)$ & - & $13(14.4)$ & $11(12.2)$ \\
\hline Staph. hominis & - & $1(3.1)$ & - & - & - & - & - & $1(1.1)$ \\
\hline Staph. lugdunensis & $1(3.1)$ & - & - & - & - & - & $1(1.1)$ & - \\
\hline Staph haemolyticus & - & - & - & - & $2(6.7)$ & - & $2(2.2)$ & - \\
\hline Staph. warneri & - & - & $1(3.6)$ & - & - & - & $1(1.1)$ & - \\
\hline Strep.pluranimalium & $1(3.1)$ & - & - & - & - & - & $1(1.1)$ & - \\
\hline Strep. sanguinis & $1(3.1)$ & - & - & - & - & - & $1(1.1)$ & - \\
\hline Strep.pneumoniae & - & - & $2(7.1)$ & - & - & - & $2(2.2)$ & - \\
\hline Haemophilus influenzae & $1(3.1)$ & - & - & - & - & - & $1(1.1)$ & - \\
\hline Pseudomonas aeruginosa & $1(3.1)$ & - & - & - & - & - & $1(1.1)$ & - \\
\hline Proteus mirabilis & $1(3.1)$ & $1(3.1)$ & - & - & $1(3.3)$ & - & $2(2.2)$ & $1(1.1)$ \\
\hline Citrobacter koseri & $1(3.1)$ & - & - & - & $1(3.3)$ & - & $2(2.2)$ & - \\
\hline Sphingomonas paucimobilis & $1(3.1)$ & - & - & - & - & - & $1(1.1)$ & - \\
\hline Neisseria elongata & - & - & $1(3.6)$ & - & - & - & $1(1.1)$ & - \\
\hline \multicolumn{9}{|l|}{ Preoperative nasal culture } \\
\hline No bacteria isolated & - & $1(3.1)$ & $1(3.6)$ & $1(3.6)$ & - & - & $1(1.1)$ & $2(2.2)$ \\
\hline MSSA & $5(15.6)$ & $7(21.9)$ & $8(28.6)$ & $7(25.0)$ & $4(13.3)$ & $3(10.0)$ & $17(18.9)$ & $17(18.9)$ \\
\hline MRSA & - & - & - & - & $3(10.0)$ & $3(10.0)$ & $3(3.3)$ & $3(3.3)$ \\
\hline Staph. epidermidis & $25(78.1)$ & $23(71.9)$ & $16(57.1)$ & $19(67.9)$ & $20(66.7)$ & $19(63.3)$ & $61(67.8)$ & $61(67.8)$ \\
\hline Staph.hominis & $1(3.1)$ & $1(3.1)$ & $1(3.6)$ & - & - & - & $2(2.2)$ & $1(1.1)$ \\
\hline Staph. haemolyticus & - & - & $1(3.6)$ & - & $2(6.7)$ & $2(6.7)$ & $3(3.3)$ & $2(2.2)$ \\
\hline Strep.pneumoniae & - & - & $1(3.6)$ & $1(3.6)$ & - & $1(3.3)$ & $1(1.1)$ & $2(2.2)$ \\
\hline Pseudomonas aeruginosa & - & - & - & - & $1(3.3)$ & $1(3.3)$ & $1(1.1)$ & $1(1.1)$ \\
\hline Serratia marcescens & - & - & - & - & - & $1(3.3)$ & - & $1(1.1)$ \\
\hline Sphingomonas paucimobilis & $1(3.1)$ & - & - & - & - & - & $1(1.1)$ & - \\
\hline \multicolumn{9}{|l|}{ Lacrimal sac culture } \\
\hline $\begin{array}{l}\text { No bacteria isolated } \\
\text { Aerobic bacteria }\end{array}$ & $19(59.4)$ & - & $4(14.3)$ & - & $16(53.3)$ & - & $39(43.3)$ & - \\
\hline MSSA & $1(3.1)$ & - & $6(21.4)$ & - & $4(13.3)$ & - & $11(12.2)$ & - \\
\hline MRSA & - & - & $1(3.6)$ & - & $1(3.1)$ & - & $2(2.2)$ & - \\
\hline Staph.epidermidis & $4(12.5)$ & - & $11(39.3)$ & - & $5(16.7)$ & - & $20(22.2)$ & - \\
\hline Staph. Iugdunensis & $1(3.1)$ & - & - & - & - & - & $1(1.1)$ & - \\
\hline Staph. haemolyticus & - & - & $1(3.6)$ & - & $1(3.1)$ & - & $2(2.2)$ & - \\
\hline Corynebacterium jeikeium & - & - & $1(3.6)$ & - & - & - & $1(1.1)$ & - \\
\hline Strep. pluranimalium & $1(3.1)$ & - & - & - & - & - & $1(1.1)$ & - \\
\hline Strep. mitis & $1(3.1)$ & - & $1(3.6)$ & - & - & - & $2(2.2)$ & - \\
\hline Strep. pneumonia & - & - & $1(3.6)$ & - & - & - & $1(1.1)$ & - \\
\hline Strep.pyogenes & - & - & $1(3.6)$ & - & - & - & $1(1.1)$ & - \\
\hline Haemophilus influenzae & $1(3.1)$ & - & - & - & - & - & $1(1.1)$ & - \\
\hline Pseudomonas aeruginosa & $1(3.1)$ & - & - & - & $1(3.1)$ & - & $2(2.2)$ & - \\
\hline Serratia marcescens & - & - & - & - & $1(3.1)$ & - & $1(1.1)$ & - \\
\hline Citrobacter koseri & $1(3.1)$ & - & - & - & $1(3.1)$ & - & $2(2.2)$ & - \\
\hline Sphingomonas paucimobilis & $1(3.1)$ & - & - & - & - & - & $1(1.1)$ & - \\
\hline Kocuria kristinae & - & - & $1(3.6)$ & - & - & - & $1(1.1)$ & \\
\hline \multicolumn{9}{|l|}{ Anaerobic bacteria } \\
\hline Bacteroides fragilis & $1(3.1)$ & - & - & - & - & - & $1(1.1)$ & - \\
\hline \multicolumn{9}{|c|}{ First postoperative week conjunctival culture } \\
\hline No bacteria isolated & $26(81.2)$ & - & $27(96.4)$ & - & $26(86.7)$ & - & $79(87.8)$ & - \\
\hline Staph. aureus & - & - & - & - & $1(3.3)$ & - & $1(1.1)$ & - \\
\hline Staph. epidermidis & $6(18.8)$ & - & $1(3.6)$ & - & $3(10.0)$ & - & $10(11.1)$ & - \\
\hline \multicolumn{9}{|c|}{ Second postoperative week conjunctival culture* } \\
\hline No bacteria isolated & $27(87.1)$ & - & $25(100.0)$ & - & $29(96.7)$ & - & $81(94.1)$ & - \\
\hline Staph. aureus & - & - & - & - & $1(3.3)$ & - & $1(1.2)$ & - \\
\hline Staph. epidermidis & $3(9.7)$ & - & - & - & - & - & $3(3.5)$ & - \\
\hline Staph. hominis & $1(3.2)$ & - & - & - & - & - & $1(1.2)$ & - \\
\hline \multicolumn{9}{|c|}{ Third postoperative week conjunctival culture* } \\
\hline No bacteria isolated & $4(66.7)$ & - & $2(100.0)$ & - & $3(100.0)$ & - & $9(81.8)$ & - \\
\hline Staph. epidermidis & $2(33.3)$ & - & - & - & - & - & $2(18.2)$ & - \\
\hline \multicolumn{9}{|c|}{ Fourth postoperative week conjunctival culture* } \\
\hline No bacteria isolated & $2(66.7)$ & - & - & - & $1(100.0)$ & - & $3(75.0)$ & - \\
\hline Staph. aureus & $1(33.3)$ & - & - & - & - & - & $1(25.0)$ & - \\
\hline
\end{tabular}

Values are presented as number (percentage). I= involved eye; C= contralateral eye; MSSA= methicillin-sensitive Staph. aureus; MRSA= methicillin-resistant Staph. aureus.

${ }^{*}=$ at the second, third, and fourth postoperative week, conjunctival culture specimens of the involved side were taken from 86,11 , and 4 patients, respectively. 
Table 3. Bacterial growth rate and normalization time according to study group

\begin{tabular}{|c|c|c|c|c|c|}
\hline & EX-DCR $(n=32)$ & EN-DCR $(n=28)$ & TC-DCR $(n=30)$ & Total $(n=90)$ & $p$ value \\
\hline \multicolumn{6}{|c|}{ Preoperative conjunctival site bacterial growth, $\mathrm{n}(\%)$} \\
\hline Involved side & $15(46.9)$ & $12(42.9)$ & $9(30.0)$ & $36(40.0)$ & $0.372^{\mathrm{aj}}$ \\
\hline Contralateral side & $11(34.4)$ & $8(28.6)$ & $2(6.7)$ & $21(23.3)$ & $0.026^{\mathrm{aj}}$ \\
\hline$p$ value & & & & $0.004^{\mathrm{b}, \mathrm{e}}$ & \\
\hline \multicolumn{6}{|c|}{ Preoperative nasal site bacterial growth, $\mathrm{n}(\%)$} \\
\hline Involved side & $32(100.0)$ & $27(96.4)$ & $30(100.0)$ & $89(98.9)$ & $0.326^{\mathrm{aj}}$ \\
\hline$p$ value & & & & $1.000^{\mathrm{bff}}$ & \\
\hline \multicolumn{6}{|c|}{ Intraoperative lacrimal sac bacterial growth, $\mathrm{n}(\%)$} \\
\hline Involved side & $13(40.6)$ & $24(85.7)$ & $14(46.7)$ & $51(56.7)$ & $0.001^{\mathrm{aj}}$ \\
\hline$p$ value & $0.727^{\mathrm{b}, \mathrm{g}}$ & $0.002^{\mathrm{b}, \mathrm{g}}$ & $0.180^{\mathrm{b}, \mathrm{g}}$ & $0.011^{\mathrm{b}, \mathrm{g}}$ & \\
\hline \multicolumn{6}{|c|}{ First postoperative week conjuntival site bacterial growth, n (\%) } \\
\hline \multicolumn{6}{|c|}{ Conjunctival flora growth } \\
\hline No growth & $1.29 \pm 0.85$ & $1.00 \pm 0.00$ & $1.24 \pm 0.54$ & $1.19 \pm 0.59$ & \\
\hline Growth & $1.67 \pm 1.29$ & $1.08 \pm 0.29$ & $1.00 \pm 0.00$ & $1.31 \pm 0.89$ & \\
\hline$p$ value & $0.292^{c, k}$ & $0.248^{c, k}$ & $0.168^{c, k}$ & $0.659^{c, k}$ & \\
\hline \multicolumn{6}{|c|}{ Lacrimal sac flora growth } \\
\hline No growth & $1.26 \pm 0.81$ & $1.00 \pm 0.00$ & $1.06 \pm 0.25$ & $1.15 \pm 0.59$ & \\
\hline Growth & $1.77 \pm 1.36$ & $1.04 \pm 0.20$ & $1.29 \pm 0.61$ & $1.29 \pm 0.81$ & \\
\hline$p$ value & $0.159^{c, k}$ & $0.683^{c, k}$ & $0.218^{c, k}$ & $0.264^{c, k}$ & \\
\hline
\end{tabular}

EX-DCR= external dacryocystorhinostomy; EN-DCR= endoscopic dacryocystorhinostomy; TC-DCR= transcanalicular multidiode laser dacryocystorhinostomy.

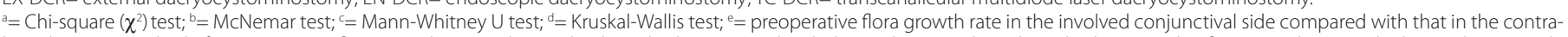

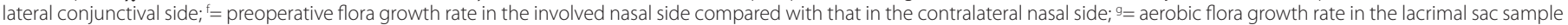

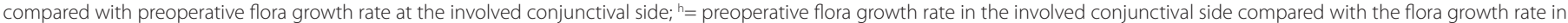

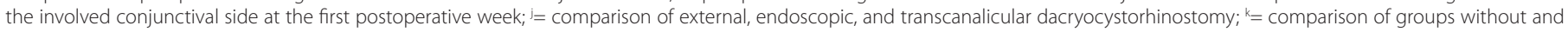
with growth based on sterilization week.

(7.8\%, 1.1\%, 22.2\%, 14.4\%, 8.9\%, and 22.2\%, respectively). Anatomical and functional success rates did not correlate with preoperative conjunctival and lacrimal sac bacterial growth rates.

Methicillin-resistant S. aureus (MRSA) has been implicated in dacryocystitis $(19,20)$. In a study of dacryocystitis caused by communityonset MRSA, Kotlus et al. ${ }^{(20)}$ stated that all their patients were at a risk of developing community-onset MRSA infections due to a hospitalacquired strain of MRSA as they had been hospitalized for at least 3 months for chronic or comorbid conditions prior to presenting with dacryocystitis symptoms. They detected seven patients with acute or subacute MRSA dacryocystitis between 2001 and 2003 (20). In contrast, Pradeep et al. ${ }^{(18)}$ found no MRSA in their series and stated that the flora of their patients was community acquired and not hospital acquired as they had been admitted to hospital on the day immediately prior to surgery. In the present study, only 2 patients (2.2\%) had dacryocystitis caused by MRSA. Similar to Kotlus et al. ${ }^{(20)}$, we believe obtaining cultures and performing sensitivity testing to determine whether antibiotic treatment is important for reducing the risk of exposure to MRSA in patients with dacryocystitis who do not respond to conservative treatment.

Gram-negative and anaerobic organisms have been reported to be present in 20\%-27\% and 7\%-16\% of patients with dacryocystitis, respectively ${ }^{(11,17,21,22)}$, and the incidence of these infections appears to be rising ${ }^{(10)}$. Gram-negative bacteria, including Pseudomonas aeruginosa, Enterobacter, Citrobacter spp., Haemophilus influenzae, and Escherichia coli, have also been reported as causative agents of da- cryocystitis ${ }^{(10)}$. Coden et al. ${ }^{(17)}$ reported . aeruginosa as the most common gram-negative organism in dacryocystitis at an incidence rate of $8.7 \%$. Brook et al. assessed the aerobic and anaerobic microbiology of 62 patients with dacryocystitis and reported a pure anaerobic growth rate of 32\%, with Peptostreptococcus spp. and Propionibacterium spp. being the most frequently isolated species among anaerobes. These authors obtained specimens intraoperatively and used an anaerobic transport medium to transport them to the laboratory ${ }^{(23)}$. Coden et al. ${ }^{(17)}$ found an anaerobic organism growth rate of $7.0 \%$, with Propionibacterium acnes as the most commonly isolated anaerobic organism. Proteus spp. and B. fragilis have been reported as other pathogens responsible for dacryocystitis ${ }^{(11,17,24,25)}$. In our series, the only anaerobic bacteria isolated from the lacrimal sac was $B$. fragilis (3.1\%), and this patient was in the EX-DCR group. The lower anaerobic growth rate in the present study may be attributable to difficulty in ensuring the growth of anaerobes despite lacrimal sac samples being inoculated preoperatively.

Owji et al. ${ }^{(15)}$ reported that microorganism growth rates in samples from the lacrimal sac and involved and contralateral sides of the conjunctiva in a group of patients with NLDO and chronic dacryocystitis were $100 \%, 100 \%$, and 97.5 , respectively, while those in samples from the conjunctiva of healthy subjects was $82.5 \%$. The same organism was isolated from the lacrimal sac and conjunctiva of the involved side in $90 \%$ of patients. They further reported that anaerobes, gram-negative bacteria, Corynebacterium, and Streptococcus spp. were isolated slightly more frequently from the involved 
BACTERIOLOGICAL PROFILE IN CONJUNCTIVAL, LACRIMAL SAC, AND NASAL SPECIMENS AND CONJUNCTIVAL NORMALIZATION TIME FOLLOWING EXTERNAL, ENDOSCOPIC, AND TRANSCANALICULAR MULTIDIODE LASER DACRYOCYSTORHINOSTOMY

Table 4. Preoperative conjunctival and lacrimal sac bacterial growth according to surgical success.

\begin{tabular}{|c|c|c|c|c|c|c|c|}
\hline & & \multicolumn{2}{|c|}{ Preoperative conjunctival bacterial growth, $\mathbf{n}(\%)$} & \multirow[b]{2}{*}{$p$ value } & \multicolumn{2}{|c|}{ Lacrimal sac bacterial growth, $\mathrm{n}(\%)$} & \multirow[b]{2}{*}{$p$ value } \\
\hline & & + & - & & + & - & \\
\hline \multicolumn{8}{|l|}{ EX-DCR $(n=32)$} \\
\hline \multirow[t]{2}{*}{ Anatomical success } & Successful & $13(86.7)$ & $13(76.5)$ & $0.659^{b}$ & $11(84.6)$ & $15(78.9)$ & $1.000^{\mathrm{b}}$ \\
\hline & Unsuccessful & $2(13.3)$ & $4(23.5)$ & & $2(15.4)$ & $4(21.1)$ & \\
\hline \multirow[t]{2}{*}{ Functional success } & Successful & $13(86.7)$ & $13(76.5)$ & $0.659^{b}$ & $11(84.6)$ & $15(78.9)$ & $1.000^{\mathrm{b}}$ \\
\hline & Unsuccessful & $2(13.3)$ & $4(23.5)$ & & $2(15.4)$ & $4(21.1)$ & \\
\hline Anatomical success & Unsuccessful & $4(33.3)$ & $3(18.8)$ & & $7(29.2)$ & - & \\
\hline \multirow[t]{2}{*}{ Functional success } & Successful & $8(66.7)$ & $12(75.0)$ & $0.691^{\mathrm{b}}$ & $16(66.7)$ & $4(100.0)$ & $0.295^{b}$ \\
\hline & Unsuccessful & $4(33.3)$ & $4(25.0)$ & & $8(33.3)$ & & \\
\hline \multicolumn{8}{|l|}{ TC-DCR $(n=30)$} \\
\hline \multicolumn{8}{|l|}{ Total $(n=90)$} \\
\hline \multirow[t]{2}{*}{ Anatomical success } & Successful & $28(77.8)$ & $42(77.8)$ & $1.000^{\mathrm{a}}$ & $38(74.5)$ & $32(82.1)$ & $0.394^{a}$ \\
\hline & Unsuccessful & $8(22.2)$ & $12(22.2)$ & & $13(25.5)$ & $7(17.9)$ & \\
\hline \multirow[t]{2}{*}{ Functional success } & Successful & $27(75.0)$ & $41(75.9)$ & $0.920^{\mathrm{a}}$ & $36(70.6)$ & $32(82.1)$ & $0.210^{\mathrm{a}}$ \\
\hline & Unsuccessful & $9(25.0)$ & $13(24.1)$ & & $15(29.4)$ & $7(17.9)$ & \\
\hline
\end{tabular}

EX-DCR= external dacryocystorhinostomy; EN-DCR= endoscopic dacryocystorhinostomy; TC-DCR= transcanalicular multidiode laser dacryocystorhinostomy.

${ }^{*}=$ values are presented as number (percentage); ${ }^{a}=$ Chi-square $\left(\chi^{2}\right)$ test; ${ }^{b}=$ Fisher's exact test.

Table 5. Sensitive susceptibility testing results for Staphylococcus spp. isolated from the lacrimal sac

\begin{tabular}{|c|c|c|c|}
\hline & $\begin{array}{c}\text { Sensitive for CNS } \\
\text { n (\%) }\end{array}$ & $\begin{array}{c}\text { Sensitive for S. aureus } \\
\text { n (\%) }\end{array}$ & $\begin{array}{l}\text { Sensitive for CNS and S. aureus } \\
\text { n (\%) }\end{array}$ \\
\hline Clindamycin & $16 / 21(76.2)$ & $11 / 12(91.7)$ & $27 / 33(81.8)$ \\
\hline Fosfomycin & $6 / 7(85.7)$ & $3 / 3(100.0)$ & $9 / 10(90.0)$ \\
\hline Fucidic acid & $6 / 9(66.7)$ & $5 / 0(100.0)$ & $11 / 14(78.6)$ \\
\hline Gentamicin & $13 / 18(72.2)$ & $11 / 11(100.0)$ & $24 / 29(82.8)$ \\
\hline Linezolid & $7 / 7(100.0)$ & $3 / 3(100.0)$ & 10/10 (100.0) \\
\hline Moxifloxacin & $3 / 4(75.0)$ & $3 / 3(100.0)$ & $6 / 7(85.7)$ \\
\hline Oxacillin & $5 / 18(27.8)$ & $9 / 11(81.8)$ & $14 / 29(48.3)$ \\
\hline Penicillin G & $1 / 13(\quad 7.7)$ & $0 / 9(0.0)$ & $1 / 22(4.5)$ \\
\hline Rifampicin & $8 / 13(61.5)$ & $3 / 4(75.0)$ & $11 / 17(64.7)$ \\
\hline Trimethoprim Sulfamethoxazole & 12/17 ( 70.6$)$ & 10/10 (100.0) & $22 / 27(81.5)$ \\
\hline Vancomycin & $6 / 6(100.0)$ & $3 / 3(100.0)$ & 9/9 (100.0) \\
\hline Mupirocin & $12 / 12(100.0)$ & $6 / 6(100.0)$ & 18/18 (100.0) \\
\hline
\end{tabular}

CNS= coagulase-negative Staphylococcus.

side than the contralateral normal side of the conjunctiva; however, this difference was not statistically significant, most likely due to the small sample size.
Pradeep et al. ${ }^{(18)}$ reported the microorganism growth rate from the lacrimal sac, conjunctival, and nasal samples as 48\%, 34\%, and $70 \%$, respectively. The same authors ${ }^{(18)}$ demonstrated a statistically 
significant similarity between isolates from lacrimal and nasal/conjunctival samples and stated that the commensal flora of the nose and conjunctiva may have a direct role in the pathogenesis of chronic dacryocystitis. They obtained culture specimens directly from the lacrimal sac under an operating microscope and emphasized the reduced contamination during sample collection associated with this technique compared to the other methods of collection, such as applying pressure over the lacrimal sac or waiting for purulent material to exit the lacrimal sac via reflux ${ }^{(9)}$. The microorganism growth rates from lacrimal sac samples, involved and contralateral side conjunctival and nasal samples obtained preoperatively, and involved conjunctival samples obtained at first and second postoperative week were $56.7 \%, 40 \%, 23.3 \%, 98.9 \%, 97.8 \%, 12.2 \%$, and $5.9 \%$, respectively. All bacterial growth rates were similar between the three groups, except in culture samples obtained preoperatively from the lacrimal sac and the contralateral conjunctiva. The culture positivity rate from the lacrimal sac was significantly higher in the EN-DCR than in the EX-DCR and TC-DCR groups and was higher than the culture positivity rate of samples obtained preoperatively from the involved side conjunctiva for EN-DCR cases and all cases together. The similar positivity rates for lacrimal sac cultures during EN-DCR and preoperative nasal cultures indicate that lacrimal sac samples may become contaminated with nasal flora while the lacrimal sac sample is being obtained intranasally. The positivity rate of lacrimal sac culture in endoscopic DCR may have been high for this reason. After DCR, conjunctival culture positivity rates were significantly reduced in all groups except in the TC-DCR group; this result is in close agreement with previous reported results ${ }^{(26)}$. The most significant reduction in conjunctival culture positivity after DCR was observed in the EN-DCR group. Although not statistically significant, a reduction was also observed in the TC-DCR group. This reduction may be associated with the use of topical and oral antibiotics prescribed to patients during the first postoperative week and with the elimination of the infection source (lacrimal sac) via lacrimal surgery.

In a study on 40 consecutive adult NLDO patients by Owji et al. ${ }^{(15)}$, the mean conjunctival normalization time after EX-DCR was 4.5 (range, 3-8) weeks. While the authors reported significant associations among normalization times, type of organism isolated from the lacrimal sac (particularly anaerobes and Streptococcus), a colony count of $\geq 10^{3}$, and presence of a silicone tube, they found no relationship between normalization times and the presence or duration of epiphora or the presence of previous attacks of acute dacryocystitis ${ }^{(15)}$. Furthermore, Owji et al. ${ }^{(15)}$ stated that the delay period should be at least 4 weeks after DCR as the conjunctival flora normalized after 4 weeks in $67.5 \%$ of their patients. In another study by Eshraghi et al. ${ }^{(26)}$ on the conjunctival flora and changes following EX-DCR, the mean normalization time was reported as 3.8 (range, 1-7) weeks in 38 patients with purulent regurgitation, 2.6 (range, 1-5) weeks in 33 patients without purulent regurgitation, and 3.3 weeks in all 71 patients. The authors reported significant associations among normalization times, pathogenic bacterial growth, higher colony counts, presence of a silicone tube, and purulent regurgitation (26). The most common organism to grow in the conjunctival cultures in patients with and without purulent regurgitation was $S$. epidermidis (26.3\% and $42.4 \%$, respectively) ${ }^{(26)}$. Eshraghi et al. ${ }^{(26)}$ also suggested that cataract surgery can be performed 7 weeks after DCR as conjunctival cultures were negative by this time in their series. The authors in both studies defined conjunctival normalization time as the interval between undergoing DCR and obtaining a negative culture result or as the time to achieve a colony count below that of the normal side ${ }^{(15,26)}$. The mean conjunctival normalization time was 1.47 (range, 1-5) weeks for EX-DCR, 1.04 weeks for EN-DCR (range, 1-2), and 1.17 (range, 1-3) weeks for TC-DCR in the present study. These results indicate that intraocular surgery may be scheduled after waiting for a conjunctival normalization time of approximately 5 weeks following DCR due to the risk of endophthalmitis. Furthermore, we observed no significant association between mean conjunctival normalization times and type of surgery. However, we defined conjunctival normalization time, which differs from the definitions for the same in the two above-mentioned studies ${ }^{(15,26)}$.

Pinar-Sueiro et al. reviewed the clinical records of 697 patients who had undergone EX-DCR and found S. aureus to be most sensitive to gentamicin, co-trimoxazole, rifampicin, clindamycin, vancomycin, tobramycin, mupirocin, cefuroxime-axetil, chloramphenicol, tetracycline, fusidic acid, and cefalotin (100\% sensitivity to all), while penicillin demonstrated the worst activity against S. aureus with $83.3 \%$ resistance ${ }^{(27)}$. In a study by Pradeep et al. ${ }^{(18)}$, antibiogram results demonstrated that Staphylococci represented the majority of cultured organisms (85\%), and the most effective antibiotics against it were vancomycin, amikacin, third-generation cephalosporins, and amoxyclav $(100 \%, 89 \%, 83 \%$, and $78 \%$ sensitivity, respectively). Penicillin (72\% resistance) and erythromycin (75\% resistance) were the least effective antibiotics. The authors ${ }^{(18)}$ suggested that amoxyclav and third-generation cephalosporins should be used to treat chronic dacryocystitis, while vancomycin and amikacin should be preferred in severe cases as they can be administered parenterally. Kotlus et al.(20) reported that tetracycline, trimethoprim/sulfamethoxazole, and vancomycin were the most effective antibiotics against MRSA dacryocystitis. In the present study, CNS and S. aureus, the most commonly isolated (36.7\%) microorganisms from the lacrimal sac, demonstrated the highest sensitivity to linezolid, teicoplanin, tigecycline, vancomycin, and mupirocin (antibiotic sensitivity rates of 100\% for all).

The following are the strengths of the present study: prospective design; first report to compare the culture results of EX-DCR, EN-DCR, and TC-DCR; long follow-up period; assessment of the postoperative microorganism growth rate; inclusion of anaerobic cultures of lacrimal samples; and evaluation of the antibiotic susceptibility of microorganisms isolated from the lacrimal sac. The present study also had a few limitations. We were unable to evaluate fungal pathogens and patients could not be randomized, which may be seen as a limitation; however, patient preference was considered a priority in the present study.

In conclusion, PANDO patients had similar conjunctival flora preoperatively and during the first week after undergoing EX-, EN-, and TC-DCR. A decrease in the growth rate of conjunctival cultures was observed after EX- and EN-DCR, but not after TC-DCR. CNS was the predominant organism isolated from pre- and post-operative conjunctival, pre-operative nasal, and per-operative lacrimal sac samples in all groups. The most significant bacterial growth in the culture sample from the lacrimal sac was observed in the EN-DCR group. Bacterial growth in pre-operative conjunctiva and pre-operative lacrimal sac samples was not associated with the success rate of DCR. Mean conjunctival normalization times were similar between the three groups at 1.47 weeks for EX-DCR, 1.04 weeks for EN-DCR, and 1.17 weeks for TC-DCR. It is necessary to wait for approximately 5 weeks for conjunctival normalization after DCR before planning intraocular surgery due to the risk of endophthalmitis. Greater understanding of the association between lacrimal flora and lacrimal surgery outcomes may facilitate the development of new strategies in treating PANDO. Further studies on the clinico-bacteriological outcomes of different surgical techniques in larger study samples are therefore required.

\section{REFERENCES}

1. Shun-Shin GA1, Thurairajan G. External dacryocystorhinostomy--an end of an era? Br J Ophthalmol. 1997;81(9):716-7.

2. Massaro BM, Gonnering RS, Harris GJ. Endonasal laser dacryocystorhinostomy. A new approach to nasolacrimal duct obstruction. Arch Ophthalmol. 1990;108(8):1172-6.

3. Woog JJ, Metson R, Puliafito CA. Holmium:YAG endonasal laser dacryocystorhinostomy. Am J Ophthalmol. 1993;116(1):1-10.

4. Hartikainen J, Grenman R, Puukka P, Seppä H. Prospective randomized comparison of external dacryocystorhinostomy and endonasal laser dacryocystorhinostomy. Ophthalmology. 1998;105(6):1106-13. 
5. Athanasiov PA, Prabhakaran VC, Mannor G, Woog JJ, Selva D. Transcanalicular approach to adult lacrimal duct obstruction: a review of instrument and methods. Ophthalmic Surg Lasers Imaging. 2009:40(2):149-59

6. Meister EF, Otto M, Rohrwacher F, Mozet C. [Current recommendations of dacryocystorhinostomy]. Laryngorhinootologie. 2010;89(6):338-44. German.

7. Roithmann R, Burman T, Wormald PJ. Endoscopic dacryocystorhinostomy. Braz J Otorhinolaryngol. 2012;78(6):113-21.

8. Piédrola Maroto D, Franco Sánchez J, Reyes Eldblom R, Monje Vega E, Conde Jiménez M, Ortiz Rueda M. [Endonasal versus trans-canalicular endoscopic dacriocystorhinostomy using diode laser. Surgical techniques and outcomes]. Acta Otorrinolaringol Esp. 2008;59(6):283-7. Spanish.

9. Pinar-Sueiro S, Sota M, Lerchundi T, Gibelalde A, Berasategui B, Vilar B, Hernandez JL. Dacryocystitis: systematic approach to diagnosis and therapy. Curr Infect Dis Rep. 2012;14(2):137-46.

10. Briscoe D, Rubowitz A, Assia El. Changing bacterial isolates and antibiotic sensitivities of purulent dacryocystitis. Orbit. 2005;24(2):95-8.

11. Hartikainen J, Lehtonen OP, Saari KM. Bacteriology of lacrimal duct obstruction in adults. Br J Ophthalmol. 1997;81(1):37-40.

12. Chaudhary M, Bhattarai A, Adhikari SK, Bhatta DR. Bacteriology and antimicrobial susceptibility of adult chronic dacryocystitis. Nepal J Ophthalmol. 2010;2(2):105-13.

13. Balikoglu-Yilmaz M1, Yilmaz T, Taskin U, Taskapili M, Akcay M, Oktay MF, Eren S. Prospective comparison of 3 dacryocystorhinostomy surgeries: external versus endoscopic versus transcanalicular multidiode laser. Ophthal Plast Reconstr Surg. 2014; 31(1):13-8.

14. Badhu BP, Karki BS, Khanal B, Dulal S, Das H. Microbiological patterns of chronic dacryocystitis. Ophthalmology. 2006;113(12):2377.e1-2.

15. Owji N, Khalili MR. Normalization of conjunctival flora after dacryocystorhinostomy. Ophthal Plast Reconstr Surg. 2009;25(2):136-8.
16. Bharathi MJ, Ramakrishnan R, Maneksha V, Shivakumar C, Nithya V, Mittal S. Comparative bacteriology of acute and chronic dacryocystitis. Eye (Lond), 2008:22(7):953-60.

17. Coden DJ, Hornblass A, Haas BD. Clinical bacteriology of dacryocystitis in adults. Ophthal Plast Reconstr Surg. 1993;9(2):125-31.

18. Pradeep AV, Patil SS, Koti SV, Arunkumar JS, Garag SS, Hegde JS. Clinico-bacteriological study of chronic dacryocystitis cases in northern karnataka, India. J Clin Diagn Res. 2013;7(11):2502-4.

19. Kubo M, Sakuraba T, Arai Y, Nakazawa M. Dacryocystorhinostomy for dacryocystitis caused by methicillin- resistant Staphylococcus aureus: report of four cases. Jpn J Ophthalmol. 2002;46(2):177-82.

20. Kotlus BS, Rodgers IR, Udell IJ. Dacryocystitis caused by community-onset methicillinresistant Staphylococcus aureus. Ophthal Plast Reconstr Surg. 2005;21(5):371-5

21. Huber-Spitzy V, Steinkogler FJ, Huber E, Arocker-Mettinger E, Schiffbänker M. Acquired dacryocystitis: microbiology and conservative therapy. Acta Ophthalmol (Copenh). 1992;70(6):745-9.

22. Seal DV, Barrett SP, McGill Jl. Aetiology and treatment of acute bacterial infection of the external eye. Br J Ophthalmol. 1982:66(6):357-60.

23. Brook I, Frazier EH. Aerobic and anaerobic microbiology of dacryocystitis. Am J Ophthalmol. 1998:125(4)552-4.

24. Evans AR, Strong JD, Buck AC Combined anaerobic and coliform infection in acute dacryocystitis. J Pediatr Ophthalmol Strabismus. 1991;28(5):292.

25. McKeag D, Kamal Z, McNab AA, Sheorey H. Combined coliform and anaerobic infection of the lacrimal sac. Clin Experiment Ophthalmol. 2002;30(1):52-4.

26. Eshraghi B, Masoomian B, Izadi A, Abedinifar Z, Falavarjani KG. Conjunctival bacterial flora in nasolacrimal duct obstruction and its changes after successful dacryocystorhinostomy surgery. Ophthal Plast Reconstr Surg. 2014;30(1):44-6.

27. Pinar-Sueiro S, Fernández-Hermida RV, Gibelalde A, Martínez-Indart L. Study on the effectiveness of antibiotic prophylaxis in external dacryocystorhinostomy: a review of 697 cases. Ophthal Plast Reconstr Surg. 2010;26(6):467-72.

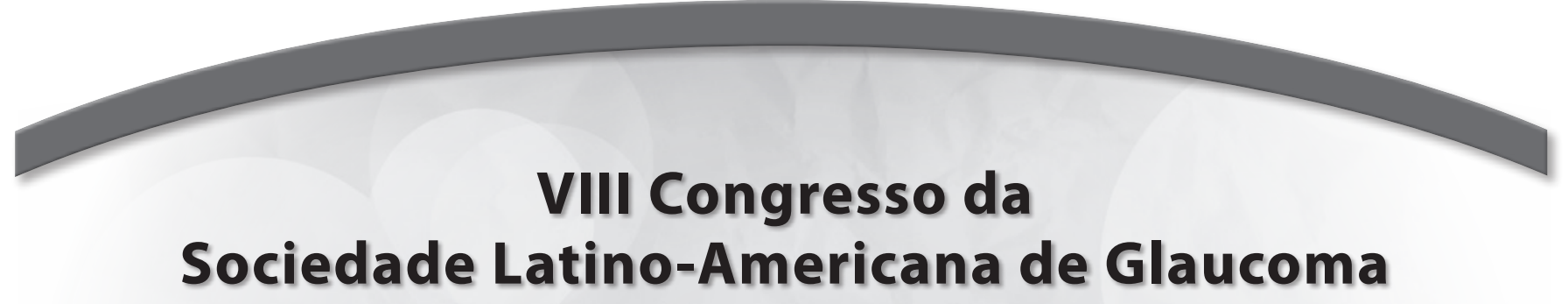

60 Congresso da Sociedade Peruana de Glaucoma

\author{
4 e 5 de novembro de 2016
}

Hotel Los Delfines

Lima - Peru

Informações:

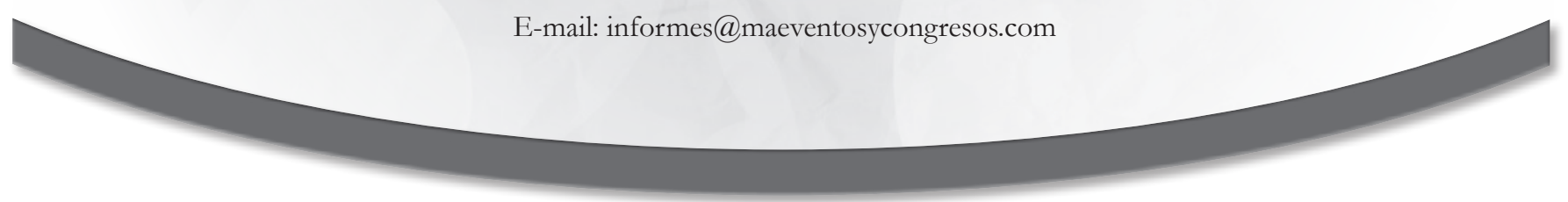

